WellBeing International

WBI Studies Repository

$12-1997$

\title{
Farrowing Behaviour and Stillbirth in Two Environments: An Evaluation of the Restraint-Stillbirth Hypothesis
}

D. Fraser

Centre for Food and Animal Research

P. A. Phillips

Centre for Food and Animal Research

B. K. Thompson

Centre for Food and Animal Research

Follow this and additional works at: https://www.wellbeingintlstudiesrepository.org/repbeh

Part of the Animal Studies Commons, Behavior and Ethology Commons, and the Comparative Psychology Commons

\section{Recommended Citation}

Fraser, D., Phillips, P. A., \& Thompson, B. K. (1997). Farrowing behaviour and stillbirth in two environments: an evaluation of the restraint-stillbirth hypothesis. Applied Animal Behaviour Science, 55(1-2), 51-66.

This material is brought to you for free and open access by WellBeing International. It has been accepted for inclusion by an authorized administrator of the WBI Studies Repository. For more information, please contact wbisr-info@wellbeingintl.org.

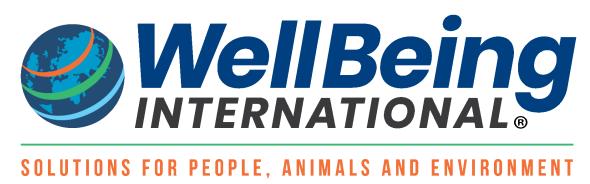




\title{
Farrowing Behaviour and Stillbirth in Two Environments: An Evaluation of the Restraint- Stillbirth Hypothesis
}

\author{
David Fraser, P.A. Phillips, B.K. Thompson
}

Centre for Food and Animal Research

\begin{abstract}
KEYWORDS
sows, piglets, farrowing behaviour, stillbirth, farrowing crate, stress
\end{abstract}

\begin{abstract}
A total of 59 farrowings were studied in either a conventional, narrow farrowing crate ( $0.43 \mathrm{~m}$ wide) or a much wider alternative design with sides spaced $1.2 \mathrm{~m}$ apart at the sow's standing height but narrowing near the floor to limit the sow's lying area. Using video recording, we monitored each "birth interval" (i.e. the period between two successive births) and noted the interval's length, the sow's posture and postural changes during the interval, and whether the interval ended with a live-born or stillborn piglet. The wide and conventional crates did not differ significantly in median interval between piglets (15.9 versus $16.0 \mathrm{~min}$, respectively), incidence of stillbirth (5.8 versus $7.0 \%$ ), in any measures of posture or postural change, or in piglet survival and weight gain to 3 days of age. Sows were most active during the first two birth intervals; as farrowing continued they made progressively fewer postural changes and spent more time lying. Sows differed greatly in the frequency of postural changes and the time they spent in different postures; however, these measures were largely unrelated to stillbirths, except that stillbirths were rare if the sow sat during much of the interval $(P<0.001)$. Birth intervals were longer, on average, before a stillbirth (median of $34 \mathrm{~min}$ ) than before a live birth $(13 \mathrm{~min} ; P<0.001)$. The greater incidence of stillbirths late in the farrowing was associated with a greater proportion of long birth intervals late in the farrowing, and greater likelihood of stillbirth even for shorter and medium intervals. Stillbirths were more common in longer farrowings $(P=0.01)$, evidently because these tended to involve larger litter sizes and more long birth intervals of over $60 \mathrm{~min}$. However, the proportion stillborn in a litter was not correlated with median birth interval. The results of this and related studies suggest that greater freedom of movement in the farrowing environment does not consistently produce shorter duration of farrowing or a lower incidence of stillbirth.
\end{abstract}

\section{Introduction}

The effect of the farrowing environment on the duration of farrowing and the incidence of stillbirth has been the subject of much discussion but few clear conclusions. Early research showed that the likelihood of intra-partum stillbirth (i.e. piglets dying during the birth process) is much increased in prolonged farrowings (Friend et al., 1962; MacDonald et al., 1963). This was explained by Randall (1972a,b) who proposed that most intra-partum stillbirths are caused by asphyxiation when the oxygen supply to a piglet 
is interrupted through damage to the umbilical cord before the piglet is expelled. In prolonged farrowings, piglets expelled after a long delay are more likely to be asphyxiated or suffer some degree of hypoxia.

Baxter and Petherick (1980) speculated that the farrowing environment could be responsible for prolonging farrowing and increasing the rate of stillbirth. Noting that adrenaline, which is released in response to short-term stress, counteracts the effect of oxytocin, which causes contraction of smooth muscle in the uterus, Baxter and Petherick (1980) hypothesized that frustration of natural nest-building behaviour among sows in restrictive farrowing crates causes stress which contributes to inefficient expulsion of piglets. Based on this logic, they proposed "that restriction immediately prior to parturition may decrease sow productivity by increasing the incidence of stillborn piglets."

Even without the involvement of endocrine changes caused by stress, there is reason to suspect that the restriction of body movement caused by farrowing crates might impede the efficient delivery of piglets. Jones (1966) described body movements of the sow that he believed to aid in the expulsion of piglets. Fraser and Broom (1990) described movements of the sow's legs and body which "force out fluids" and they suggested that a fetus may be expelled at the same time. Hence, close confinement of sows during farrowing might restrict movement, delay the expulsion of piglets, and lead to more stillbirths.

In previous work (Fraser et al., 1988), we developed a wide farrowing crate which allows the sow to turn around and go through most natural postural changes unimpeded. In the present study, we monitored farrowings closely in this crate and in a conventional, restrictive crate. The objectives were: (1) to determine whether the timing of expulsion of piglets and incidence of stillbirth is influenced by the additional freedom of movement in the wide crate, (2) to examine relationships between stillbirths, the time taken to expel a piglet, and postural changes by the sow, and (3) to provide a fürther test of piglet survival and weight gain in the wide crate design versus a conventional crate during farrowing and early lactation.

\section{Methods}

\subsection{Farrowing facilities}

The wide crate (Fig. 1) was a slightly revised prototype of the design described by Fraser et al. (1988). The sow's area was located diagonally in a square pen of $1.95 \mathrm{~m} \times 1.95 \mathrm{~m}$. The two sides of the crate were vertical partitions of tubular steel covered in solid sheet metal, spaced $1.2 \mathrm{~m}$ apart at the sow's standing height (interior dimension). Tubular steel "fingers" were angled inward, toward the sow, at the bottom of these partitions to restrict the sow's lying area to a width of $750 \mathrm{~mm}$. The conventional crate was a commercial model; each side consisted of three straight, horizontal steel tubes spaced $470 \mathrm{~mm}$ apart on centre giving an interior width of $430 \mathrm{~mm}$ at the sow's standing height, and a fourth (lowest) horizontal tube, $235 \mathrm{~mm}$ above the floor, which was flared outward from the sow to give an interior width of $740 \mathrm{~mm}$ at the sow's lying height. All farrowings were monitored in one room containing a crate of each type.

\subsection{Animals and procedures}

The study involved 59 farrowings in a minimum-disease Yorkshire and Yorkshire $\times$ Landrace herd. Sows were moved into the crates 5 days before farrowing was expected, and remained there until the piglets were 3 days old, by which age most piglet deaths have normally occurred (English and Smith, 1975). When one of the experimental crates became available, it was filled with the next available sow in the herd's farrowing cycle, with the following provisions. (1) The few sows that were judged to be too large to fit the conventional crate were omitted from the experiment entirely to avoid any bias in allocating sows to crates on the basis of body size. (2) If both crates were empty, sows were allocated to one or the other at 
random unless sows of that animal's parity class (divided as parity $1,2-3,4-6$, or $7+>$ were needed to balance the distribution of parity classes between the two crate-types. (3) In the eight cases where a sow returned to the experiment for a second farrowing, it was always assigned to the crate it had not occupied the previous time. In most cases (50 of the 59 ) the sow was weighed when moved into the crate.

The data involved two phases: farrowing and rearing. Farrowing records included the total number of piglets born (excluding mummified foetuses), the number of these that were stillborn, and the number that died before the first weighing of the animals on the day after birth. The rearing phase started at this first weighing and ended 3 days later when the piglets were reweighed and the sow and litter were removed from the room. Rearing data thus included weight gains and the number of deaths during the three-day interval. A small amount of cross-fostering was done before the first weighing for normal operation of the herd. This involved adding ten piglets to litters in the wide crate and twelve to litters in the conventional crate, and removing five piglets from litters in the wide crate and three from the conventional.

Fig. 1. The wide farrowing crate used in the experiment. The crate is wide enough at the sow's standing height to permit her to turn around. The inward slope of the side walls restricts the lying area to a size typical of more restrictive crates, and the slope helps to control the movements of the sow as she lies down.

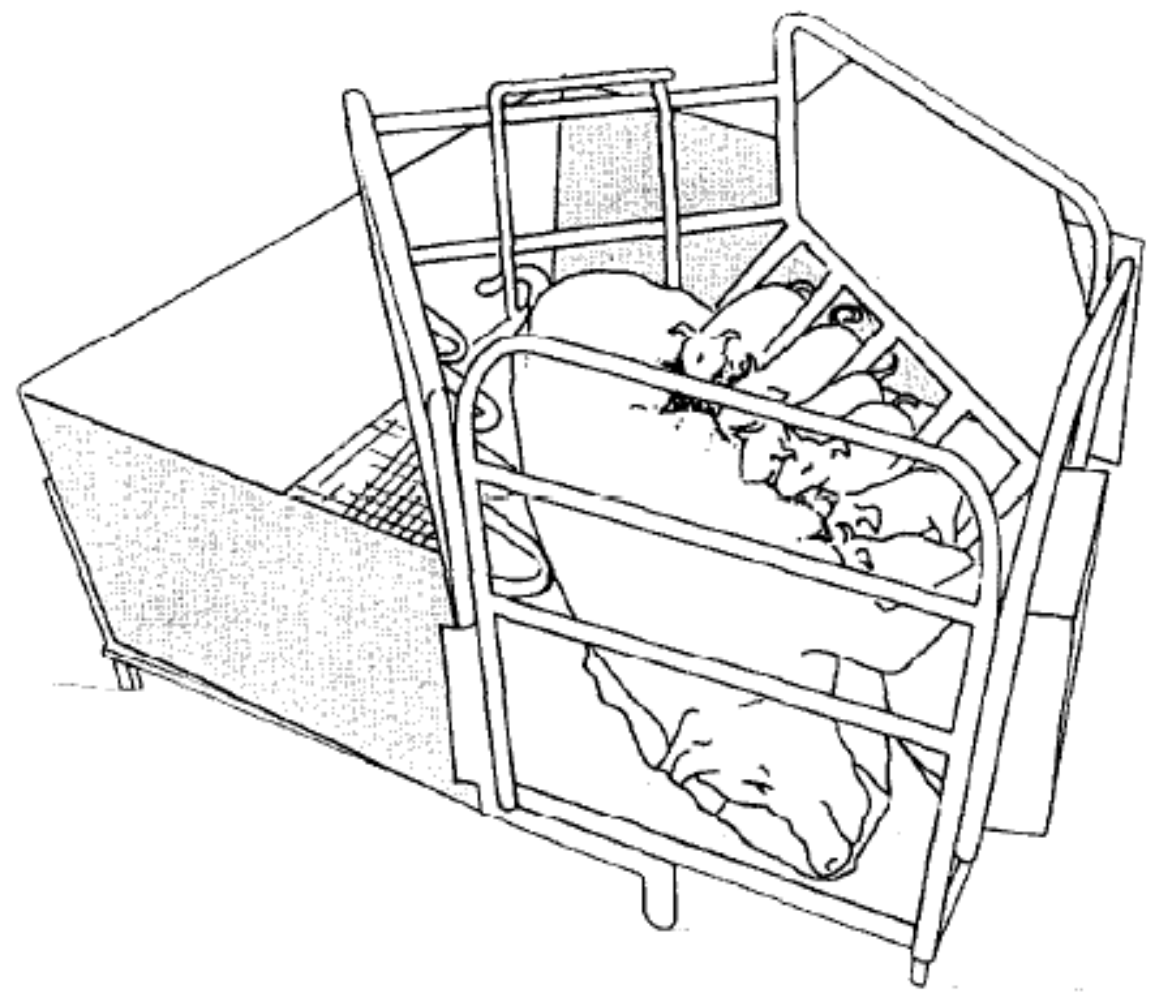

\subsection{Monitoring of fürrowing behaviour}

Each farrowing was monitored by time-lapse video recording. One camera gave a wide-angle view of the sow from the side to identify times when the sow changed posture between standing, sitting and lying. Two or three additional cameras provided a detailed view of the rear of the sow to record the expulsion of piglets. The images from the cameras, together with a time and date signal, were combined on a single monitor by a four-way splitter (Model TC1474, RCA, Lancaster PA, USA) and were recorded by a video recorder (Model AG6720, Panasonic, Secausus NJ, USA) at a speed of 30 frames per minute. 
During analysis of the video records, notes were made on (1) the time when each piglet was born, (2) whether the piglet was born alive or stillborn, and (3) the time of each change of posture (between standing, sitting, and lying) by the sow. Analysis began with the birth of the first piglet and ended with the birth of the last, except that postural changes were not recorded for the final interval in two farrowings because an unexpected extra piglet was born several hours later, after the recording had ended. A piglet was considered stillborn if it was an apparently full-term fetus that made no visible movement after birth as seen on the video recording. This criterion presumably covered all piglets dying of asphyxiation during the birth process, including the small minority of asphyxiated animals that retain some detectable pulse and feeble gasping reflex before dying several minutes after birth (Randall, 1971). The behavioural criterion (no visible movement) avoids the common error of misclassifying piglets as stillborn if they are mobile at birth but die from crushing or other causes before the litter is first inspected (Edwards et al., 1994). The few cases of decomposing fetuses (which had evidently died well before parturition) were not included.

For each "birth interval" (i.e. the time elapsed between the birth of two successive piglets), the records provided: (1) the length of the interval in minutes; (2) whether the interval ended in a stillborn or live-born piglet; and (3) seven postural variables. These were: the proportions of the interval that the sow spent standing, sitting and lying (three variables); the number of times that the sow changed posture to standing, sitting or lying, expressed per $10 \mathrm{~min}$ (three variables); and the sum of the last 3 variables, yielding the total number of postural changes per $10 \mathrm{~min}$ in the interval.

\subsection{Statistical analysis}

Least-squares analysis of variance (PROC GLM of SAS Institute Inc., 1989) was used to test for differences between the two crate types in the time taken to expel the piglets and the incidence of stillbirth. As a measure of the time taken to expel the piglets, the median birth interval (used instead of the mean to avoid undue impact of a few unusually long intervals) was calculated for each farrowing. As a measure of the incidence of stillbirths, the number of stillborn piglets was expressed as a proportion of total piglets (excluding any decomposing fetuses) in each litter. For these between-litter comparisons the "basic model" for analysis of variance included (1) sow parity number, (2) litter size (i.e. total number of live and stillborn piglets), (3) crate type, tested after variation owing to the first two factors had been taken into account, and (4) interactions of crate type with parity number and litter size. For both parity number and litter size, the linear effect was included first, followed by the remaining (non-linear) variation. To test whether any effect of parity was due to differences in litter size, the analysis was repeated with litter size included first. To test whether the effects of parity number and litter size were related to differences in sow body weight, the analyses were repeated (using the 50 sows with complete body weight data) with sow body weight included both before and after the effects of parity number and litter size. To test whether the incidence of stillbirths was related to sow postural variables, seven analyses were conducted, each including one of the postural variables (expressed for the entire farrowing) with the basic model.

To test how different aspects of the duration of farrowing contributed to the incidence of stillbirth, leastsquares analysis of variance was applied using proportion stillborn as the dependent variable and total length of farrowing (after logarithmic transformation to reduce the impact of a few large values) as the independent. The analysis was then repeated four times, each time adding an additional variable to the model (before total length of farrowing) in the order: (1) litter size; (2) median birth interval; (3) proportion of birth intervals over $30 \mathrm{~min}$; and (4) proportion of birth intervals over $60 \mathrm{~min}$. As each variable was introduced, we tested whether the relation between the proportion stillborn and total length of farrowing remained significant. 
To study variables influencing the distribution of stillbirth within a farrowing, piglets were divided into five groups to reflect the order in which they were born. The first group consisted of the first piglet born in each litter as there was no relevant birth interval for this animal. The remaining piglets were divided into four quartiles ranging from the first to the last farrowed in each litter. (Quartiles were used instead of actual birth order to avoid the impact of having different numbers of intervals in different farrowings.) Each birth interval was coded as 0 if the piglet was born alive or 1 if the piglet was stillborn. For each of the seven postural variables, a least-squares analysis of variance was applied to these 0,1 values using a model that first took account of the between-sow variation (crate type and sow identity), then (1) the quartile, from first to fourth, in which the interval fell, (2) the length of the interval in minutes, (3) the relevant postural variable, and (4) interactions of these variables with crate type. Although these data were discrete and hence did not conform to the normal distribution, least-squares analysis of variance was considered appropriate as discussed by Harvey (1982).

\section{Results}

Farrowing and rearing performance were similar in the two crates (Table 1). All of the differences were well within sampling error. Total losses (stillbirths, deaths before the first weighing, and deaths before 3 days of age) accounted for 30 of the 311 piglets in the wide crate and 30 of the 316 in the conventional crate. For purposes of comparison, results from a previous study using the same crate designs (Fraser et al., 1988) are also included in Table 1.

Table 1. Performance of piglets during the fat-rowing phase (birth to first weighing) and early rearing phase (subsequent 3 days) for the two farrowing crate types; corresponding results from a previous study (Fraser et al., 1988) are shown for comparison

\begin{tabular}{|c|c|c|c|c|c|c|c|}
\hline \multirow[t]{2}{*}{ Crate type } & \multicolumn{3}{|c|}{ Farrowing phase } & \multicolumn{4}{|c|}{ Rearing phase } \\
\hline & $\begin{array}{l}\text { Total } \\
\text { piglets }\end{array}$ & Stillbirths & $\begin{array}{l}\text { Deaths to first } \\
\text { weighing }\end{array}$ & $\begin{array}{l}\text { Total } \\
\text { piglets }\end{array}$ & Deaths & $\begin{array}{l}\text { Mean liveweight } \\
\text { gain (g per day }{ }^{d}\end{array}$ & $\begin{array}{l}\text { Mean within-litter } \\
\text { variance in gain }^{\mathrm{e}}\end{array}$ \\
\hline \multicolumn{8}{|l|}{ Present Study } \\
\hline Wide & $311^{a}$ & $18(5.8 \%)$ & $9(3.1 \%)$ & $289^{a}$ & $3(1.0 \%)$ & 133 & 2039 \\
\hline Conventional & $316^{a}$ & $22(7.0 \%)$ & $2(0.7 \%)$ & $301^{a}$ & $6(2.0 \%)$ & $134(\mathrm{SEM}=7)$ & $1902(\mathrm{SEM}=289)$ \\
\hline \multicolumn{8}{|l|}{ Previous Study } \\
\hline Wide & $230^{b}$ & $23(10.0 \%)$ & $10(4.8 \%)$ & $183^{\mathrm{C}}$ & $8(4.4 \%)$ & 192 & 1811 \\
\hline Conventional & $190^{b}$ & $23(12.1 \%)$ & $1(0.6 \%)$ & $167^{\mathrm{c}}$ & $10(6.0 \%)$ & $198($ SEM = 8) & $1751($ SEM = 467) \\
\hline
\end{tabular}

${ }^{\mathrm{a}}$ Based on 29-30 litters per crate.

${ }^{\mathrm{b}}$ Based on 18-20 litters per crate.

${ }^{\mathrm{c}}$ Based on 16-18 litters per crate after fostering.

${ }^{d}$ Based on a S-day period in the present study and a 13-day period in the previous study.

e Mean of within-litter variances.

\subsection{Farrowing behaviour}

Sows in both crates were generally more active during the first few birth intervals, and then became steadily less active as the farrowing progressed. In the first interval, sows averaged over 2 postural changes per $10 \mathrm{~min}$, and spent only $60-65 \%$ of the time lying (Fig. 2). Postural changes became less frequent as the farrowing progressed, and the animals spent more time lying and less time sitting and standing. These trends were very similar in the two farrowing crates. Postural changes per $10 \mathrm{~min}$ averaged 1.05 in the wide crate versus 1.09 in the conventional crate. The percentage of time spent lying, standing and sitting averaged 86,8 and $6 \%$ respectively in the wide crate, versus 88,6 and $6 \%$ in the 
conventional crate. Sows in the wide crate turned around a median of two times during the farrowing (range of 0-28 times). Turning was most common in the first and second birth intervals and rare thereafter.

Fig. 2. Mean (with SEM) number of postural changes per $10 \mathrm{~min}$ (above), and mean percentage of time spent lying (below) in the first eight birth intervals, for sows in conventional crates (open circles) and wide crates (filled circles). The analysis was limited to the $\mathbf{4 9}$ sows that produced nine or more piglets, yielding the full eight intervals for each sow.
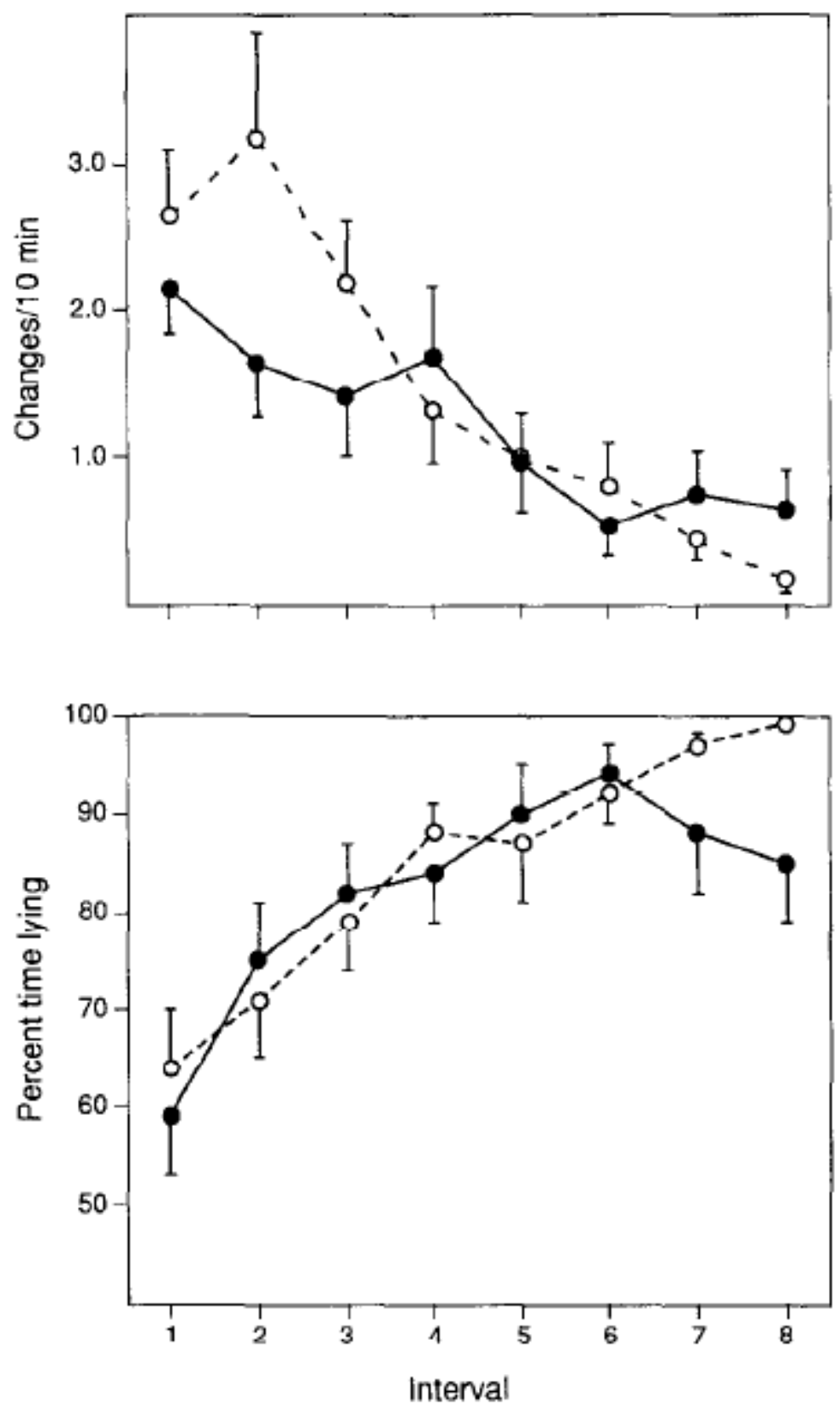

There were large differences between farrowings in the time taken to expel the piglets. Two exceptional cases were omitted from fürther analysis. One was a sow in the wide crate who produced four live piglets at exceptionally long intervals (median of 117 min between piglets) followed by two stillborn piglets 
several hours later. Another sow, in the conventional crate, lay without any change of posture for $8 \mathrm{~h}$ before delivering piglets; she then produced three stillborn piglets, followed by nine others at a median of 5 min apart. In this case we assume that the delivery of the first piglets was delayed by blockage in the reproductive tract so that the short time elapsed between first and last piglets did not reflect the actual duration of parturition. With these sows omitted, the number of stillborn piglets ranged from 0 to 3 per litter in both crate types, the median birth interval of the farrowings ranged from 3.5 to $40 \mathrm{~min}$, and the mean of the litter medians was 15.9 min for the wide crate and 16.0 min for the conventional.

Analysis of variance of median birth interval (based on the remaining 57 litters) showed no difference between the two crates, a tendency for median interval to decrease as a linear effect of increasing litter size $(P<0.05)$ but no trends with sow parity number or body weight, and no interactions of these factors with crate type.

Table 2. Changes in stillbirths and birth interval length during the course of farrowing

\begin{tabular}{|c|c|c|c|c|c|c|c|c|}
\hline \multirow[t]{2}{*}{$\begin{array}{l}\text { Piglet birth } \\
\text { sequence }\end{array}$} & \multicolumn{3}{|c|}{ Number of piglets } & \multicolumn{2}{|c|}{$\begin{array}{l}\text { Median birth interval } \\
\text { (minutes) }\end{array}$} & \multicolumn{3}{|c|}{$\begin{array}{l}\text { Number of intervals } \\
\text { (and percentage stillborn) }\end{array}$} \\
\hline & $\begin{array}{l}\text { Born } \\
\text { alive }\end{array}$ & Stillborn & $\begin{array}{l}\text { Percentage } \\
\text { stillborn }\end{array}$ & $\begin{array}{l}\text { Ending in } \\
\text { live birth }\end{array}$ & $\begin{array}{l}\text { Ending in } \\
\text { stillbirth }\end{array}$ & $<30$ min & $30-60 \mathrm{~min}$ & $>60 \mathrm{~min}$ \\
\hline First piglet & 55 & 2 & 3.5 & --- & --- & --- & --- & --- \\
\hline \multicolumn{9}{|c|}{ Subsequent piglets: } \\
\hline First quartile & $115^{\mathrm{a}}$ & 3 & 2.5 & 16 & 62 & $81(0.0 \%)$ & $26(3.8 \%)$ & $11(18.2 \%)$ \\
\hline Second quartile & 142 & 3 & 2.1 & 12 & 10 & $121(2.5 \%)$ & $14(0.0 \%)$ & $10(0.0 \%)$ \\
\hline Third quartile & 124 & 7 & 5.3 & 11 & 12 & $112(5.4 \%)$ & 14 (7.1\%) & $5(0.0 \%)$ \\
\hline Fourth quartile & 138 & 20 & 12.7 & 15 & 52 & $111(6.3 \%)$ & $27(14.8 \%)$ & $20(45.0 \%)$ \\
\hline Total & 574 & 35 & 5.7 & 13 & 34 & & & \\
\hline
\end{tabular}

${ }^{a}$ The formula used for assigning intervals to quartiles led to unequal numbers per quartile when the number of birth intervals in a farrowing was not divisible by 4 .

\subsection{Stillbirths}

Stillbirths occurred throughout the farrowings, but were much more common toward the end, especially if a long delay preceded the expulsion of the piglet. Stillbirths were most common in the last quartile $(12.7 \%$ stillborn) and lowest in the first and second (approximately 2\%) with intermediate values for piglets born first in the litter or in the third quartile (Table 2).

The median birth interval preceding a stillbirth was $34 \mathrm{~min}$, compared to only $13 \mathrm{~min}$ for intervals preceding a live birth. Median birth interval was longer in the first and last quartiles than in the middle of the farrowing (Table 2). Intervals ending in stillbirth were distinctly prolonged in the first and last quartiles but not in the few stillbirths that occurred in the second and third quartiles (Table 2). The high percentage of stillbirths in the final quartile appeared to be related in part to the occurrence of many long birth intervals in this quartile, but even so, more than half of the stillbirths in this quartile occurred after intervals of short or medium length (Table 2).

Analysis of variance of the stillbirth values (indicating whether a birth interval ended in a stillbirth or a live birth) showed a highly significant effect of quartile number $(P<0.01$, reflecting the trend toward more stillbirths in the last quartile), and of interval length $(P<0.001$, reflecting the trend for long intervals to end in stillbirth). With these variables in the model, the proportion of time the sow sat during the interval was 
related $(P<0.001)$ to the likelihood of stillbirth: the greater the proportion of time the sow spent sitting, the less the likelihood of stillbirth. All other postural variables were non-significant.

Fig. 3. Percentage of stillborn piglets (mean \pm SEM of litter values) in relation to (a) total duration of farrowing in minutes, from the first to the last piglet, (b) median length of the interval between successive births. (c) litter size (total number of piglets born alive and stillborn), and (d) sow parity number. The number of litters in each category is shown in parentheses.
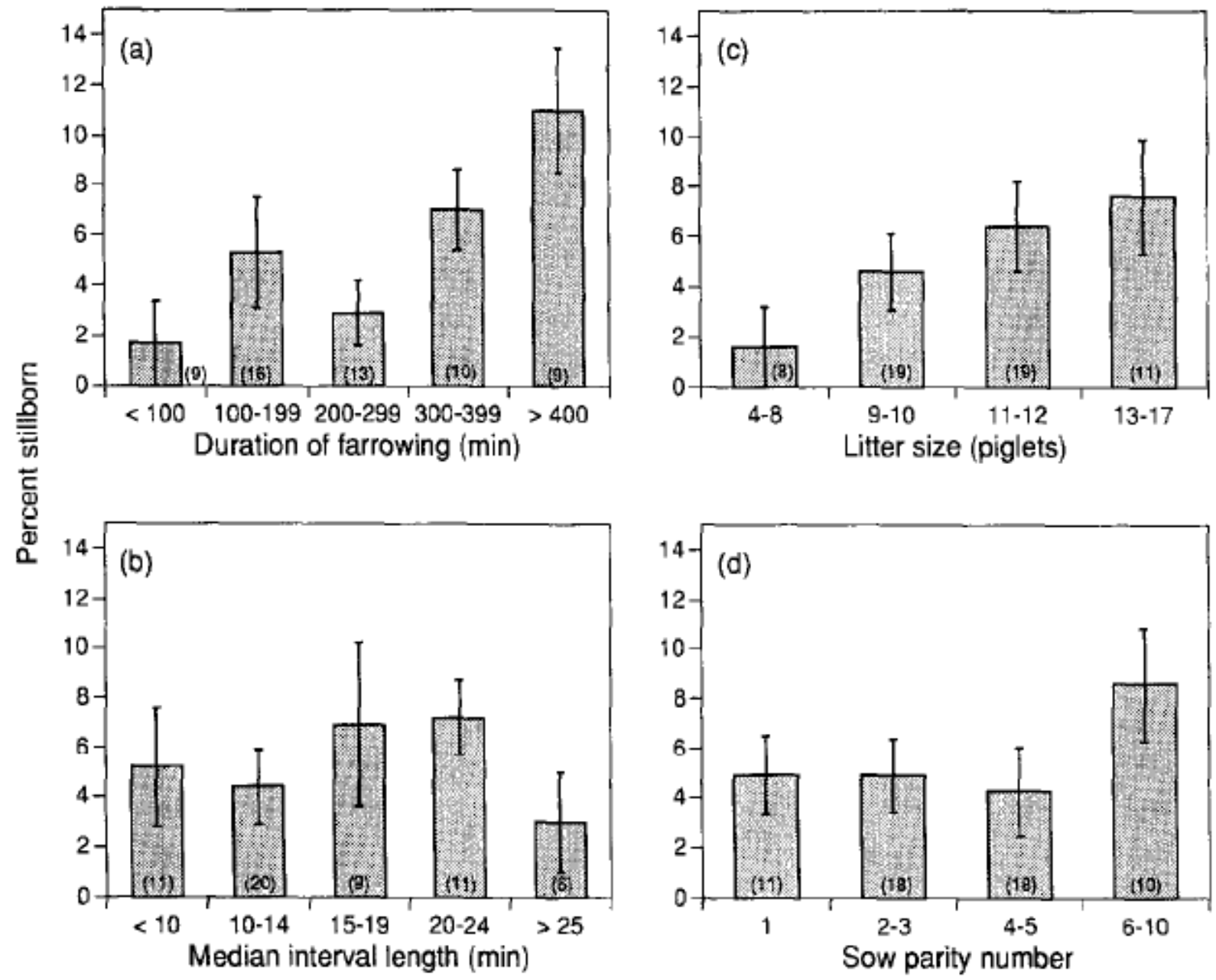

The proportion of piglets that were stillborn in a litter increased from $2 \%$ for short farrowings of less than $100 \mathrm{~min}$, to $11 \%$ for the longest of over $400 \mathrm{~min}$ (Fig. 3(a)). On a litter basis, most litters (8/9) had no stillborn piglets in the shortest farrowings, whereas most (also 8/9) had at least one stillbirth with the longest farrowings. However, there was little tendency for the proportion stillborn to be greater if the median interval between births was high: as median interval rose from less than 10 min to 25 min or more, there was little increase in either the percentage of piglets stillborn (Fig. 3(b)) or the percentage of litters with stillbirth. Analysis of variance showed that the proportion stillborn was significantly related $(P \approx$ $0.01)$ to the total length of farrowing when this was the only independent variable: the effect remained significant $(P<0.05)$ after variation owing to litter size was taken into account. Neither median birth interval nor the proportion of intervals over 30 min were significantly related to the proportion stillborn, but the proportion of intervals over 60 min was highly related to proportion stillborn $(P<0.01)$ and with this 
variable included in the model, the relation between proportion stillborn and total length of farrowing was no longer significant $(P \approx 0.25)$.

The proportion stillborn tended $(P \approx 0.1)$ to be higher among sows of high parity number and with a large number of piglets born (Fig. 3(c) and Fig. 3(d)). With these effects in the model, there was no relation ( $P>$ 0.05 ) between the proportion stillborn and crate type, sow body weight, or any of the postural variables, and no interaction of crate type with other variables.

\section{Discussion}

The conventional crate, with an interior width of only $430 \mathrm{~mm}$ at the sow's standing height, barely exceeded the width of the sow's body in most cases, whereas the wide crate provided approximately triple this width and permitted the sows to go through most postural changes unimpeded. In choice tests sows showed a clear preference for the wide design over more restrictive ones (Phillips et al., 1992). Nonetheless there were no apparent differences between the two environments in the duration of farrowing, the number of postural changes or in the time spent in the different postures apart from the fact that turning was impossible in the conventional crate. As with our previous study (Fraser et al., 1988) the wide and the conventional crate also gave similar rates of stillbirth, piglet deaths, and early weight gains, with no differences approaching statistical significance $(P>0.05)$, although deaths in the early hours (before the piglets were first weighed) tended to be greater in the more spacious crate.

The results help to clarify some aspects of stillbirth in domestic pigs. The analysis suggests that the well known tendency for stillbirth rate to increase late in the farrowing (Friend and Cunningham, 1966; Randall, 1972b) involves two factors: (1) an increase in the incidence of long birth intervals late in the farrowing, and (2) greater likelihood of stillbirth even with intervals of short or medium duration. The well known tendency for long farrowings to produce more stillbirths (Friend et al., 1962; MacDonald et al., 1963; Bille et al., 1974; Randall, 1972b) also appears to involve two factors: (1) greater litter size, as large litters tended to have longer farrowings and a greater proportion stillborn, and (2) more stillbirths in farrowings with some exceptionally long intervals (over $60 \mathrm{~min}$ ) between births. However, there was little tendency for stillbirths to increase with the median interval between births. This suggests that attempts to reduce stillbirths by manipulating the duration of farrowing (e.g. Sprecher et al., 1974, 1975) are more likely to be effective if they eliminate unusually long birth intervals rather than shortening birth intervals that are already within a normal range.

Most measures of the sow's posture and postural change were uncorrelated with the incidence of stillbirth. However, the adoption of a sitting posture may have helped to expel piglets, as stillbirths were less common the more the sow sat during the preceding interval.

\subsection{The "restraint-stillbirth" hypothesis}

The "restraint-stillbirth" hypothesis of Baxter and Petherick (1980) proposes that stress caused by the prevention of normal pre-farrowing behaviour in restrictive crates results in endocrine changes that slow the delivery of piglets and lead to more stillbirths. This hypothesis has important implications for both animal welfare and efficient pig production. Although cited repeatedly, the hypothesis has been subject to little critical evaluation.

If sufficiently extreme, disturbance during parturition can delay the delivery of fetuses in various animal species including the pig (Naaktgeboren, 1979). For example, in an experiment by Lawrence et al. (1992), human handlers moved sows to an unfamiliar environment while farrowing was in progress, and observed a clear lengthening of the interval between piglets. The question, therefore, is not whether disturbance can delay the farrowing process but whether the degree of restriction in commercial farrowing 
crates is sufficient to increase the duration of farrowing and the incidence of stillbirth. The hypothesis is arguably too general to be tested by any single experimental comparison, but it has helped to stimulate several lines of research seeking links between the farrowing environment and stillbirth rate.

Table 3. Results of studies reporting stillbirth rates in crates versus pens or enlarged crates

\begin{tabular}{|c|c|c|c|c|c|}
\hline \multicolumn{2}{|c|}{ Percent stillborn } & \multicolumn{2}{|c|}{ Number of litters } & \multirow[t]{2}{*}{ Source } & \multirow[t]{2}{*}{ Remarks } \\
\hline Crates & Alternative & Crates & Alternative & & \\
\hline \multicolumn{6}{|c|}{ Crates versus pens $^{a}$} \\
\hline 4.5 & 4.3 & 80 & 40 & $\begin{array}{l}\text { Svendsen and } \\
\text { Andeŕasson, } 1980\end{array}$ & "Intra-partum" stillbirths only \\
\hline 5.4 & 4.5 & 83720 & 15607 & Gustafsson, 1983 & "Stillborn" was "dead before or during birth" \\
\hline 7.1 & 4.2 & $\approx 40$ & $\approx 40$ & Parry, 1986 & $\begin{array}{l}\text { Crates versus bedded pens. Ten sows per } \\
\text { treatment over four parities }\end{array}$ \\
\hline $7.1^{\mathrm{e}}$ & $3.0^{\mathrm{e}} / 17.6^{\mathrm{e}}$ & 11 & $10 / 9$ & McGlone and Blecha, 1987 & $\begin{array}{l}\text { Standard crate }(7.1 \% \text { stillborn) versus outdoor } \\
\text { heated pen }(3.0 \%) \text { or heavily bedded hut } \\
(17.6 \%) \text {. Means of least square means }\end{array}$ \\
\hline $8.1^{\mathrm{e}}$ & $7.8^{\mathrm{e}}$ & 20 & 20 & $\begin{array}{l}\text { McGlone and Morrow- } \\
\text { Tesch, } 1990\end{array}$ & Means of least square means ${ }^{b}$ \\
\hline 0.0 & 9.4 & 12 & 12 & Cronin et al., 1991 & Crates versus bedded pens \\
\hline$\approx 2$ & $\approx 3$ & 32 & 32 & Cronin and Smith, 1992 & Values are approximate $^{c}$ \\
\hline 5.9 & 4.4 & 50 & 43 & Arey et al., 1992a & $\begin{array}{l}\text { Individually housed sows in crates or large } \\
\text { bedded pens }\end{array}$ \\
\hline 4.4 & 4.5 & 8 & 8 & Blackshaw et al.. 1994 & \\
\hline \multicolumn{6}{|c|}{ Crates versus enlarged crates } \\
\hline $7.1^{\mathrm{e}}$ & $6.5^{\mathrm{e}}$ & 11 & 11 & McGlone and Blecha, 1987 & $\begin{array}{l}\text { Standard versus flared "turn-around" crates. } \\
\text { Means of least square means }\end{array}$ \\
\hline 11.2 & 10.0 & 58 & 20 & Fraser et al., 1988 & Wide crate versus three conventional designs \\
\hline 3.1 & 4.8 & 104 & 107 & Curtis et al., 1989 & Narrow $(55 \mathrm{~cm})$ versus wide $(64 \mathrm{~cm})$ crates $^{d}$ \\
\hline 15.7 & 8.3 & 32 & 32 & Lou and Hurnik, 1994 & $\begin{array}{l}\text { Large ellipsoid crate versus conventional } \\
\text { design }\end{array}$ \\
\hline 7.0 & 5.8 & 29 & 30 & Present study & Wide crate versus conventional design \\
\hline
\end{tabular}

${ }^{a}$ Other relevant studies include Hansen and Vestergaard (1984) who compared stillbirth rates for sows tethered during farrowing (8.1\%) versus untethered in similar pens (5.7\%); Gertken et al. (1993) who compared sows farrowing in crates (3.9\% stillborn) versus freeaccess pens in a group housing system (3.3\%); and McGlone et al. (1994) who compared crates (5.8\% stillborn for gilts, $1.9 \%$ for sows) versus a girth-tether system (5.6\% for gilts, $5.1 \%$ for sows).

${ }^{\mathrm{b}}$ In this factorial experiment, sloped versus level floors had no significant effect on stillbirth rate.

${ }^{\mathrm{c}}$ In this factorial experiment, provision of straw also gave a non-significantly higher stillbirth rate than no straw.

${ }^{d}$ In this factorial experiment, longer crates $(198 \mathrm{~cm})$ also gave a higher stillbirth rate than short ones $(183 \mathrm{~cm})$.

eIn these results "stillborn" was defined as found dead within $12 \mathrm{~h}$ after birth.

Firstly, consistent with the present results, few studies have shown that provision of additional space during farrowing has a major effect on stillbirth rate (Table 3) or farrowing duration. In a large survey, Gustafsson (1983) found a slightly higher average stillbirth rate on farms with confined versus unconfined sows, and in a small study Weber and Troxler (1988) reported longer farrowings in crates than in pens. However, other studies have shown no tendency toward fewer stillbirths in pens or enlarged crates (Svendsen and Andréasson, 1980; Fraser et al., 1988; McGlone and Morrow-Tesch, 1990; Blackshaw et al., 1994). Curtis et al. (19891 reported the reverse trend, with significantly fewer stillbirths in shorter and narrower crates compared to more spacious ones, despite a weak tendency toward longer farrowings in 
the smaller crates (Rohde Parfet et al., 1989). In the one study reporting a strong link between space allowance and stillbirths, Lou and Humik (1994) found substantially fewer stillbirths in a large, modified crate, but the result appeared to reflect an exceptionally high stillbirth rate in their conventional crate $(15.7 \%)$ rather than a low rate in the spacious one (8.3\%). On the whole, differences reported within studies are usually small, and different studies provide no consistent trend toward fewer stillbirths in farrowing pens or larger crates compared to conventional crates. In fact, of the 13 studies listed in Table 3 , the more restrained sows (in conventional crates) had higher stillbirth rates in eight studies, while the less restrained sows (in pens or enlarged crates) had higher stillbirth rates in five studies $(P \approx 0.3$ by the sign test).

Secondly, there is no clear evidence that provision of nest-building material in a farrowing crate shortens farrowing or reduces stillbirths. In two small studies, the incidence of stillbirth was not affected when sows farrowing in crates were provided with chopped straw (Edwards and Fumiss, 1988) or straw and visual cover (Cronin and van Amerongen, 1991). However, Cronin et al. (1993) studied 174 sows on a commercial farm where human handlers provided half of the sows with handfuls of sawdust once or twice per hour, for a number of hours before farrowing. In this case, provision of sawdust was associated with shorter farrowing and fewer intra-partum stillbirths (2.3\% versus $5.5 \%)$ but only for sows of parities $1-3$, while older sows showed a non-significant trend in the opposite direction.

In the above cases neither additional space alone (without bedding) nor bedding alone (in a confined space) appeared to have much effect. Other studies show that the combination of bedding plus additional space does not consistently reduce stillbirth rate. McGlone and Blecha (1987) reported a very high stillbirth rate $(17.6 \%)$ in heavily bedded huts compared to unbedded crates (Table 3); however, their "stillbirths" included all piglets found dead within $12 \mathrm{~h}$ after birth. Arey et al. (1992a), comparing data from different research facilities, found that sows farrowing in large, bedded, single-sow pens showed only a slightly lower incidence of stillbirth (4.4 versus 5.9\%) than sows in crates (Table 3). Parry (1986) also found a non-significant trend toward more stillbirths and longer parturition in sows farrowing in crates compared to large bedded pens (Table 3). However, Cronin et al. (1991) found a higher stillbirth rate in 12 gilts farrowing in bedded pens (9.4\%) compared to 12 farrowing in unbedded crates $(0.0 \%)$. In a factorial experiment, Cronin and Smith (1992) studied 64 litters farrowed either in crates or pens, and either with or without straw; stillbirths were slightly (non-significantly) more common in pens than in crates (about 3 versus 2\%, Table 3), and with straw than without (4 versus 1\%), although a subset of 24 sows from the same study (Cronin et al., 1994) showed some tendency for longer birth intervals in crates, specifically by the six sows farrowing in crates without straw (G.M. Cronin, personal communication, 1995).

Finally, studies that have varied the environment during both gestation and parturition have provided fürther conflicting evidence. Svendsen and Bengtsson (1984) found no differences in duration of farrowing or incidence of stillbirth between various pen and crate environments used at farrowing, but longer farrowings among sows that had been housed in stalls, rather than loose-housed, during pregnancy. Similarly, Svendsen and Andréasson (1980) found no difference in duration of farrowing or stillbirth rate between sows farrowing in pens versus two types of crate, but did detect an effect of housing during pregnancy, with longer farrowings and a trend toward more stillbirths (5.3 versus 3.6\%) in sows housed in stalls rather than loose-housed during pregnancy. In contrast, Parry (1986) found no differences attributable to the gestation environment, and Cronin and Simpson (1993) found more stillbirths in sows that had been housed in pens rather than stalls during gestation, and more stillbirths in sows that fan-owed in crates rather than two-sow pens; they suggested that sows housed in pens during gestation and then confined in crates for farrowing might be especially at risk. Vestergaard and Hansen (1984) found shorter farrowing times for 12 sows loose-housed during both pregnancy and farrowing 
(mean of $234 \mathrm{~min}$ ) compared to 34 sows that were tethered during either or both of these periods (mean of about $340 \mathrm{~min}$ ). They attributed the prolonged farrowing to both stress during parturition and lack of exercise during pregnancy.

Out of these conflicting results, two studies deserve fürther attention because of very low stillbirth rates seen in particular treatments. In the study of Cronin et al. (1993), provision of sawdust involved frequent human disturbance (once or twice per hour) before farrowing; younger sows receiving this treatment were more active before farrowing and subsequently had very few intra-par-turn stillbirths (2.3\%). Similarly, a very low stillbirth rate (3.1\%) was reported by Arey et al. (1992a) for 51 sows farrowing in pairs, where some aggression between pen-mates before farrowing evidently occurred (Arey et al., 1992b). These two results may be chance effects. However, in an outdoor environment, sows normally walk many kilometres during the day before farrowing as they seek and prepare a nest site (Jensen, 1986). Sows farrowing in confinement also become more active on the day before farrowing (Phillips et al., 1991), but still spend most of the day lying down. As a speculative hypothesis, we suggest that disturbance during the day before farrowing, caused by human activity in the study of Cronin et al. (1993) and by the presence of a pen-mate in the study of Arey et al. (1992a), may have stimulated enough additional pre-farrowing activity in the sows to lead to more efficient delivery of piglets and a lower stillbirth rate.

In conclusion, although the restraint-stillbirth hypothesis has intuitive appeal and a plausible physiological mechanism, studies have not shown any clear or consistent tendency for provision of additional space and/or nest-building material to reduce the duration of farrowing or the incidence of stillbirth. The hypothesis need not be dismissed entirely; for example, future research might test whether stillbirth rates are lower when sows can perform their natural nest-seeking and nest-building in totally unconfined environments, or when high levels of pre-farrowing activity are achieved in other ways. However, the type of modifications to the farrowing environment studied to date seem ineffective in reducing the important losses occasioned by stillborn piglets.

\section{Acknowledgements}

We are grateful to Dr. G.M. Cronin for most valuable discussion on these issues, to Diana Alves for her diligent work on the data collection, to Zensheng Lou for compiling the behavioural records, to the staff of the CFAR pig unit for their usual excellent cooperation, and to E.A. Pajor and D.M. Weary for helpful comments on the manuscript.

\section{References}

Arey, D.S., Petchey, A.M., Fowler, V.R., 1992a. Farrowing accommodation and piglet mortality. Farm Building Progress 107, 5-7.

Arey, D.S., Petchey, A.M., Fowler, V.R., 1992b. The peri-parturient behaviour of sows housed in pairs. Applied Animal Behaviour Science 34, 49-59.

Baxter, M.R., Petherick, J.C., 1980. The effect of restraint on parturition in the sow. Proceedings of the International Pig Veterinary Society 6, 84.

Bille, N., Nielson, N.C., Larsen, J.L., Svendsen, J., 1974. Preweaning mortality in pigs. II. The perinatal period. Nordisk Veterinaermedicin 26, 294-3 13. 
Blackshaw, J.K., Blackshaw, A.W., Thomas, F.J., Newman, F.W., 1994. Comparison of behaviour patterns of sows and litters in a farrowing crate and a farrowing pen. Applied Animal Behaviour Science 39, 281-295.

Cronin, G.M., Barnett, J.L., Hodge, F.M., Smith, J.A., McCallum, T.H., 1991. The welfare of pigs in two farrowing/lactation environments: cortisol responses of sows. Applied Animal Behaviour Science 32, 117127.

Cronin, G.M., Schirmer, B.N., McCallum, T.H., Smith, J.A., Butler, K.L., 1993. The effects of providing sawdust to pre-parturient sows in farrowing crates on sow behaviour, the duration of parturition and the occurrence of intra-partum stillborn piglets. Applied Animal Behaviour Science 36, 301-315.

Cronin, G.M., Simpson, G.J., 1993. Piglet survival in a conventional crate versus an 'alternative' farrowing system. In: Batterham, E.S. (Ed.), Manipulating Pig Production IV. Australasian Pig Science Association, Attwood, Australia, p. 128.

Cronin. G.M., Smith, J.A., 1992. Effects of accommodation type and straw bedding around parturition and during lactation on the behaviour of primiparous sows and survival and growth of piglets to weaning. Applied Animal Behaviour Science 33, 191-208.

Cronin, G.M., Smith, J.A., Hodge, F.M., Hemsworth, P.H., 1994. The behaviour of primiparous sows around farrowing in response to restraint and straw bedding. Applied Animal Behaviour Science 39, 269280.

Cronin, G.M., van Amerongen, G., 1991. The effects of modifying the farrowing environment on sow behaviour and survival and growth of piglets. Applied Animal Behaviour Science 30, 287-298.

Curtis, S.E., Hurst, R.J., Widowski, T.M., Shanks, R.D., Jensen, A.H., Gonyou, H.W., Bane, D.P., Muehling, A.J., Kesler, R.P., 1989. Effects of sow-crate design on health and performance of sows and piglets. Journal of Animal Science 67, 80-93.

Edwards, S.A., Fumiss, S.J., 1988. The effects of straw in crated farrowing systems on peripartal behaviour of sows and piglets. British Veterinary Journal 144, 139-146.

Edwards, S.A., Smith, W.J., Fordyce, C., MacMenemy, F., 1994. An analysis of the causes of piglet mortality in a breeding herd kept outdoors. Veterinary Record 135, 324-327.

English, P.R., Smith. W.J., 1975. Some causes of death in neonatal piglets. Veterinary Annal 15, 95-104.

Fraser, A.F., Broom, D.M.. 1990. Farm Animal Behaviour and Welfare, 3rd ed. Bailliere Tindall. London, UK.

Fraser, D., Phillips. P.A., Thompson, B.K., 1988. Initial test of a farrowing crate with inward-sloping sides. Livestock Production Science 20, 249-256.

Friend, D.W., Cunningham, H.M., 1966. Piglet birthweights and the order of farrowing. Canadian Journal of Comparative Medicine 30, 179-182.

Friend, D.W., Cunningham, H.M., Nicholson, J.W.G., 1962. The duration of farrowing in relation to the reproductive performance of Yorkshire sows. Canadian Journal of Comparative Medicine 26, 127-130. 
Gertken, Cl., Krieter, J., Schlichting, M., Ernst, E., 1993. Untersuchungen zur integrierten Sauenhaltung unter besonderer Berlicksichtigung von Verhalten, Konstitution und Leistung. 2 Mitteilung: Konstitution und Leistung. Zuchtungskunde 65, 188-196.

Gustafsson, B., 1983. Effects of sow housing systems in practical pig production, Transactions of the ASAE 26, 1181-1193.

Hansen, L.L., Vestergaard, K., 1984. Tethered versus loose sows: Ethological observations and measures of productivity: II, production results. Annales des Recherches Vétérinaires 15, 185-191.

Harvey, W.R., 1982. Least squares analysis of discrete data. Journal of Animal Science 54, 1067-1071.

Jensen, P., 1986. Observations on the maternal behaviour of free-ranging domestic pigs. Applied Animal Behaviour Science 16, 131-142.

Jones, J.E.T.. 1966. Observations on parturition in the sow. Part II. The parturient and post-parturient phases, British Veterinary Journal 122, 471-478.

Lawrence, A.B., Petherick, J.C., McLean, K., Gilbert, C.L., Chapman, C., Russell, J.A., 1992. Naloxone prevents interruption of parturition and increases plasma oxytocin following environmental disturbance in parturient sows. Physiology and Behavior 52, 917-923.

Lou, Z., Humik, J.F., 1994. An ellipsoid farrowing crate: its ergonomical design and effects on pig productivity. Journal of Animal Science 72, 2610-2616.

MacDonald, M.A., Holness, D.E., Moxley, J.E., 1963. Some factors influencing the losses of pigs prior to weaning. Canadian Journal of Comparative Medicine and Veterinary Science 27, 237-240.

McGlone, J.J.. Blecha, F., 1987. An examination of behavioral, immunological and productive traits in four management systems for sows and piglets. Applied Animal Behaviour Science 18, 269-286.

McGlone, J.J., Morrow-Tesch, J., 1990. Productivity and behavior of sows in level vs sloped farrowing pens and crates. Journal of Animal Science 68, 82-87.

McGlone, J.J.. Salal-Johnson, J.L., Nicholson, RI., Hicks, T., 1994. Evaluation of crates and girth tethers for sows: reproductive performance, immunity. behavior and ergonomic measures. Applied Animal Behaviour Science 39, 297-311,

Naaktgeboren, C., 1979. Behavioural aspects of parturition. Animal Reproduction Science 2, 155-166.

Parry, M.A., 1986. The effect of confinement on behaviour and reproductive performance in the sow. Agricultural Progress 61, 46-54.

Phillips, P.A., Fraser, D., Thompson, B.K., 1991. Preference by sows for a partially enclosed farrowing crate. Applied Animal Behaviour Science 32, 35-43.

Phillips, P.A., Fraser, D., Thompson, B.K., 1992. Sow preference for farrowing crate width. Canadian Journal of Animal Science 72, 745-750.

Randall, G.C.B., 1971. The relationship of arterial blood $\mathrm{pH}$ and $\mathrm{pCO}_{2}$, to the viability of the newborn piglet. Canadian Journal of Comparative Medicine 35, 141-146. 
Randall, G.C.B., 1972a. Observations on parturition in the sow. I. Factors associated with the delivery of the piglets and their subsequent behaviour. Veterinary Record 90, 178-182.

Randall, G.C.B., 1972b. Observations on parturition in the sow. II. Factors influencing stillbirth and perinatal mortality. Veterinary Record 90, 183-186.

Rohde Parfet, K.A., Gonyou, H.W., Curtis, S.E., Hurst, R.J., Jensen, A.H., Muehling, A.J., 1989. Effects of sow-crate design on sow and piglet behavior. Journal of Animal Science 67, 94-104.

SAS Institute Inc., 1989. SAS/STAT User's Guide, Version 6, 4th ed., vol. 2. SAS Institute Inc., Cary, NC, USA.

Sprecher, D.J., Leman, A.D., Carlisle, S., 1975. Effects of parasympathomimetics on porcine stillbirth. American Journal of Veterinary Research 36, 1331-1333.

Sprecher, D.J., Leman, A.D., Dziuk, P.D., Cropper, M., DeDecker, M., 1974. Causes and control of swine stillbirths. Journal of the American Veterinary Medicine Association 165, 698-701.

Svendsen, J., Andréasson, B., 1980. Perinatal mortality in pigs: influence of housing. Proceedings of the International Pig Veterinary Society 6, 83.

Svendsen, J., Bengtsson, A., 1984. Perinatal mortality in pigs: factors contributory to the occurrence of intra partum dead pigs. Proceedings of the International Pig Veterinary Society 8, 369.

Vestergaard, K., Hansen, L.L., 1984. Tethered versus loose sows: ethological observations and measures of productivity. I. Ethological observations during pregnancy and farrowing. Annales des Recherches Vtterinaires 15, 245-256.

Weber, R., Troxler, J., 1988. Die Bedeutung der Zeitdauer der Geburt in verschiedenen Abferkelbuchten zur Beurteilung auf Tiergerechtheit. KTBL-Schrift (Kuratorium für Technik und Bauwesen in der Landwirtschaft) $323,172-184$. 